\title{
Infection of Soybean Seed by Fusarium graminearum and Effect of Seed Treatments on Disease Under Controlled Conditions
}

\author{
M. L. Ellis, K. D. Broders, P. A. Paul, and A. E. Dorrance, Department of Plant Pathology, The Ohio State University, Wooster 44691
}

\begin{abstract}
Ellis, M. L., Broders, K. D., Paul, P. A., and Dorrance, A. E. 2011. Infection of soybean seed by Fusarium graminearum and effect of seed treatments on disease under controlled conditions. Plant Dis. 95:401-407.

Fusarium graminearum causes seed decay and damping-off of soybean. This study evaluated the effect of inoculum density of $F$. graminearum, temperature, and fungicide seed treatments on disease development. To determine the optimum conditions for disease development, individual soybean seed was inoculated with $100 \mu \mathrm{l}$ of a suspension of $2.5 \times 10^{2}, 2.5 \times 10^{3}, 2.5 \times 10^{4}$, or $2.5 \times 10^{5}$ macroconidia/ml in a rolled-towel assay at temperatures of 18,22 , and $25^{\circ} \mathrm{C}$. Inoculum concentrations of $2.5 \times 10^{4}$ macroconidia $/ \mathrm{ml}$ or higher were necessary for optimum disease development at all temperatures. The

efficacy of captan, fludioxonil, mefenoxam + fludioxonil, azoxystrobin, trifloxystrobin, and pyraclostrobin as seed treatments was then evaluated with the same assay at $2.5 \times 10^{4}$ and $2.5 \times 10^{5}$ macroconidia $/ \mathrm{ml}$. Seed treated with captan at $61.9 \mathrm{~g}$ a.i. or fludioxonil at $2.5 \mathrm{or}$ $5.0 \mathrm{~g}$ a.i. per $100 \mathrm{~kg}$ developed smaller lesions than other seed treatments and the nontreated control. Based on these results, there are limited choices in fungicide seed treatments for managing this seedling disease, and it is possible that shifts in seed treatment products may have played a role in the recent emergence of this soybean pathogen.
\end{abstract}

A high incidence of soybean seedling disease causes poor stands, which can result in added costs of replanting and reduced yields as a result of later planting dates. The most common soybean seedling pathogens in Ohio include Pythium spp., Phytophthora sojae Kaufm. \& Gerd., and Rhizoctonia solani Kühn (teleomorph Thanatephorus cucumeris (A.B. Frank) Donk). Recently, Fusarium graminearum Schwabe (teleomorph: Gibberella zeae (Schwien.) Petch) was identified as a pathogen of soybean $(8,23,28,38,39)$. This fungus is primarily regarded as an economically important pathogen of wheat (Triticum aestivum L.), barley (Hordeum vulgare L.), and oat (Avena sativa L.), where it causes Fusarium head blight (4,24); and in corn (Zea mays L.), where it causes Gibberella ear and stalk rot (31). F. graminearum also causes seedling diseases of both corn (9) and wheat (20). In addition to its cereal hosts and soybean, $F$. graminearum has also been identified as a pathogen to several other non-cereal hosts, including dry bean (C. Bradley, personal communication), canola (11), potato (2), and sugar beet (17).

Prior to the recognition of $F$. graminearum as a significant pathogen of soybean, it had been isolated from various parts of the soybean plant as well as soybean debris $(3,5,12,15,18,19,21$, 27,33). These earlier reports were conflicting as to whether $F$. graminearum was pathogenic to soybean $(1,3,10,15,16,25,33,34)$. Wicklow et al. (33) first described $F$. graminearum as a secondary pathogen and others considered $F$. graminearum to be nonpathogenic to soybean $(10,15,16,25)$. This was due to failed attempts to complete Koch's postulates, carried out through direct inoculations of the hypocotyls of seedlings (10) or applications of spore suspensions of $F$. graminearum to flowers (15).

$F$. graminearum causes pod blight, seed and root rot, and preand post-emergence damping-off of soybean $(8,12,23,28,38,39)$. Lesions observed in artificial inoculations on the roots first appear water soaked, followed by a pinkish-brown discoloration spreading vertically in both directions (39). Lesions on seedlings observed in the field are similar to those observed in the laboratory (personal

Corresponding author: A. E. Dorrance, E-mail: dorrance.1@ osu.edu

Accepted for publication 22 November 2010.

doi:10.1094/PDIS-05-10-0317

(C) 2011 The American Phytopathological Society observation). Infections at later growth stages (R5) developed external browning and internal discoloration of the stem. Pod blight and interveinal chlorosis of the leaves followed by plant wilt and death has only been reported from Argentina (28). Seed infected by $F$. graminearum at harvest appear pink to reddish in color; however, seed infection may also be asymptomatic. Deoxynivalenol and HT-2 mycotoxins have been detected in symptomatic soybean seed infected by $F$. graminearum and F. sporotrichioides (12).

There has been an increase in occurrence of soybean seedling diseases in Ohio, such as those caused by $F$. graminearum. This may be due to earlier planting dates (prior to 10 May) where cool, moist soil conditions delay seed germination and favor the growth of soilborne pathogens $(7,8)$. In addition, no-till and reduced-tillage practices also increase seedling disease incidence and severity by creating soil conditions that are favorable for pathogen growth and survival $(15,36)$. In Ohio, producers predominantly use a cornsoybean or corn-soybean-wheat rotation in combination with reduced-tillage or no-tillage to conserve soil, prevent erosion, and increase organic matter. These practices may also favor the survival of $F$. graminearum because the fungus can overwinter on residue of all three crops $(5,13,21,35)$. Isolates of $F$. graminearum collected from wheat and corn were moderately to highly pathogenic to soybean $(8,37,39)$. Xue et al. (39) proposed that selection pressure for highly aggressive $F$. graminearum isolates may exist for this rotation.

The active ingredients used in seed-treatment fungicides have changed in the past few years, possibly contributing to an increase in seedling disease incidence in soybean. Products such as Captan (37.4\% captan; Bayer Crop Science, NC) and Rival (19.8\% captan plus $8.4 \%$ pentachloronitrobenzene plus $1.0 \%$ thiabendazole; Gustafson, Plano, TX), which were highly effective seed-treatment fungicides, are no longer commonly used. The sensitivity of $F$. graminearum to recently labeled seed-treatment fungicides such as azoxystrobin and trifloxystrobin, as well as standard fungicides fludioxonil and captan, were evaluated using amended agar plate assays. Of these fungicides, fludioxonil was the only one that inhibited mycelia growth (8). Interestingly, $F$. graminearum mutants insensitive to fludioxonil were readily generated during the laboratory assay, although none were recovered from the field (8). The efficacy of these fungicides as seed treatments for control of $F$. graminearum should be examined to confirm the results obtained from amended agar plate assays. 
The impact of $F$. graminearum as a seedling pathogen of soybean in Ohio is still unknown. The first step in addressing this question would be to determine the optimum conditions required for infection and disease development, such as inoculum concentration and temperature. The optimum conditions for germination of $F$. graminearum macroconidia are relative humidity $>80 \%$, based on in vitro studies at approximately $20^{\circ} \mathrm{C}$ in darkness (6). Conditions for vegetative growth of Fusarium spp. were a 12-h period of light at $25^{\circ} \mathrm{C}$ and a 12 -h period of darkness at $20^{\circ} \mathrm{C}(22)$. Thus, disease severity would be expected to increase at temperatures between 20 and $25^{\circ} \mathrm{C}$. However, at these warmer temperatures, soybean seed germinate more quickly than at cooler temperatures, possibly making them less susceptible to infection.

The objective of this study was to address some of the factors that may have contributed to the emergence of $F$. graminearum as a soybean pathogen by determining (i) optimal inoculum concentrations and temperature required for disease development by $F$. graminearum and (ii) the efficacy of recently labeled seed-treatment fungicides for the control of seedling disease caused by $F$. graminearum.

\section{Materials and Methods}

Isolates and inoculum preparation. Six single-macroconidia isolates of $F$. graminearum were used in this study. Isolates were collected from infected corn during spring 2004 (K95R and K85R), soybean during spring 2007 (Fay11 and Fay15), and wheat during summer 2007 (Van and Woo). All isolates were collected from symptomatic seedlings in Ohio fields and maintained on carnation leaf agar (CLA). The corn isolates were used in an earlier study by Broders et al. (8), and all other isolates used in this study were previously untested on soybean. Inoculum was prepared by growing isolates on CLA for 10 to 14 days with a 12-h light period to enhance macroconidia production. The macroconidia were dislodged into 2 to $3 \mathrm{ml}$ of sterilized water from the agar surface with a sterile glass rod. This was transferred from the plate with a pipette and filtered through three layers of cheesecloth to reduce the amount of mycelial fragments present in the inoculum. The filtered

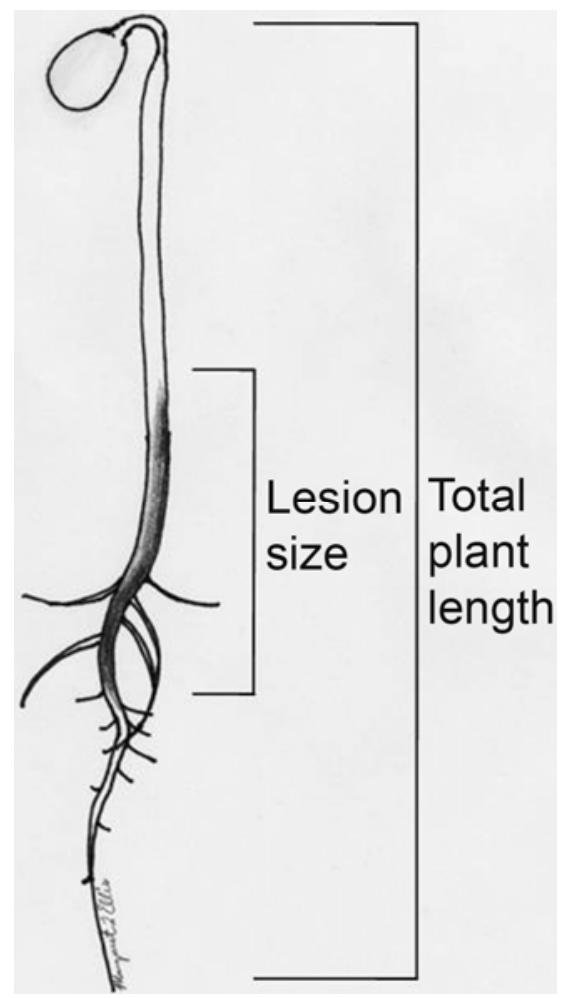

Fig. 1. Disease severity index for soybean seedlings infected with Fusarium graminearum. Disease severity index was calculated by dividing the lesion length by the total length and multiplying by 100 . macroconidial suspension was then quantified using a hemacytometer (Bright-Line Hemacytometer; Hausser Scientific, Horsham, PA) as described by Tuite (32). This was repeated four times and an average concentration was calculated. Sterile water was added to the inoculum to achieve the desired macroconidia concentrations, and the adjusted suspensions were then recounted to verify the proper concentrations.

Optimum conditions for disease development. To determine the optimum inoculum concentrations and temperature required for disease development, a rolled-towel assay was used. Twenty seeds of soybean 'Sloan', susceptible to F. graminearum, were placed in a row on a moistened towel and each seed was inoculated with a $100-\mu l$ suspension of macroconidia at one the following concentrations using the previously tested corn isolate K95R (8): $0,2.5 \times$ $10^{2}, 2.5 \times 10^{3}, 2.5 \times 10^{4}$, or $2.5 \times 10^{5}$ macroconidia/ml. Another moistened towel was placed over the inoculated seed and the towels were rolled and then placed in 25-liter buckets. The experimental design was a randomized complete block with temperature and inoculum concentration in a split-plot arrangement. Temperature was the whole plot and inoculum concentration the subplot. The experiment was repeated once, with time as the blocking factor. For each temperature, there were three towels per concentration. The towels were randomized within a bucket and care was used to avoid cross contamination from the different concentrations. A black plastic bag was then placed over each bucket, and these were placed in a growth chamber at 18,22 , or $25^{\circ} \mathrm{C}$.

After 7 days, the seedlings were rated using two methods. First, a disease severity index was calculated by measuring the root, shoot, and length of the lesion on each plant with a ruler and then dividing the lesion size by the total length and multiplying by 100 (Fig. 1). Seed that did not germinate and were colonized by $F$. graminearum were given an index rating of $100 \%$. The second method rated seedlings using a 1 -to- 5 scale, where $5=$ no germination, complete colonization of the seed; $4=$ germination, complete colonization of the seed, and $75 \%$ or more of the seedling root with lesions; 3 = germination, some colonization of seed, and 20 to $74 \%$ of the root with lesions; 2 = germination, little colonization of the root, and 1 to $19 \%$ of the root with lesions; and 1 = germination, healthy seedling with no visible signs of colonization (Fig. 2A).

The disease severity index data was arcsine transformed and analyzed using the general linear model procedure (PROC GLM) of SAS (SAS Institute Inc., Cary, NC). Means were compared using Fisher's protected least significant difference (LSD) at $P=$ 0.05 . The ordinal rating data was analyzed using a nonparametric approach as described by Shah and Madden (30) using PROC MIXED of SAS, where isolate and inoculum concentration were treated as fixed effects and the relative pathogenicity among isolates and treatments were compared using contrasts.

Pathogenicity assays. To select isolates to evaluate fungicide efficacy to $F$. graminearum, the pathogenicity of six isolates of $F$. graminearum collected from soybean (Fay11 and Fay15), corn (K85R and K95R), and wheat (Woo and Van) in Ohio was evaluated. The isolates collected from soybean and wheat had not previously been tested for pathogenicity, whereas the corn isolates had previously been tested in greenhouse assays by Broders et al. (8). The isolates were compared using the rolled-towel method and an inoculum concentration of $2.5 \times 10^{4}$ macroconidia/ml at $22^{\circ} \mathrm{C}$. Noninoculated seed were used as the check to ensure that other seed-colonizing pathogens were not present in the seed. These results were not included in final analysis. The experimental design was a randomized complete block, with each isolate randomly assigned to three separate buckets within a growth chamber. Because each bucket provided a physical separation among the replicates of the isolates and we assumed that the microenvironment was homogeneous within buckets but heterogeneous among buckets, we considered each bucket to be a block and random effect in the analysis.

The disease severity index data was arcsine-transformed and then analyzed using PROC GLM of SAS (SAS Institute Inc.). As a preliminary step in the analysis, Levene's test of homogeneity of 
variance was performed using PROC GLM and plots of the raw data were evaluated to determine whether the data from the two experiments could be pooled. Because the test was not statistically significant $(P=0.08)$, the experiments were combined and analyzed as one. The transformed means were compared using Fisher's protected LSD at $P=0.05$.

Fungicide efficacy assay. Soybean seed was treated with one of the following fungicides: captan at $61.9 \mathrm{~g}$ a.i. (Captan 400; Bayer Crop Science), fludioxonil at $2.5 \mathrm{~g}$ a.i. (Maxim 4S; Syngenta Crop Protection Inc., NC), fludioxonil at $5.0 \mathrm{~g}$ a.i. (Maxim 4S), azoxystrobin at $1.0 \mathrm{~g}$ a.i (Dynasty; Syngenta Crop Protection Inc.), azoxystrobin at $3.0 \mathrm{~g}$ a.i. (Dynasty), and mefenoxam + fludioxonil at $3.75+2.5$ g a.i. (Apron Maxx RTA; Syngenta Crop Protection Inc.) per $100 \mathrm{~kg}$. Fungicide-treated seed were placed on towels as described above and each seed was inoculated with a $100-\mu l F$. graminearum spore suspension. The experimental design was completely randomized, with a factorial arrangement of inoculum concentration $\left(2.5 \times 10^{4}\right.$ or $2.5 \times 10^{5}$ macroconidia/ml $)$, fungal isolate (Fay11 and K95R), and fungicide seed treatment. Nontreated seed were used as checks. Noninoculated and nontreated seed for all treatments were also included to verify seed health but were not included in the statistical analysis. The buckets were placed in an incubator at $22^{\circ} \mathrm{C}$ and rated after 7 days using both methods described previously. This experiment was done three times.

Levene's test of homogeneity of variance and raw data plots were used as previously described to compare experiments, and data from the three experiments were pooled for analysis. Disease severity index data were arcsine-transformed and analyzed using PROC GLM of SAS (SAS Institute Inc.). Means were compared using Fisher's protected LSD at $P=0.05$. Data for the ordinal rating scale were analyzed using a nonparametric approach as described by Shah and Madden (30). The ordinal rating was analyzed using PROC MIXED of SAS where isolate, inoculum concentra- tion, and fungicide treatments were treated as fixed effects while the relative pathogenicity and fungicide efficacy among isolates and treatments were compared using contrasts.

Strobilurin fungicide efficacy assay. A separate rolled-towel assay was used to evaluate the strobilurin fungicides azoxystrobin at $3.0 \mathrm{~g}$ a.i. (Dynasty), trifloxystrobin at $10.0 \mathrm{~g}$ a.i. (Trilex; Bayer Crop Science), and pyraclostrobin at $9.9 \mathrm{~g}$ a.i. (Stamina; BASF Corp., NC) per $100 \mathrm{~kg}$. The experiment was similar to the previous fungicide seed treatment experiment except that only one isolate, Fay11, and only one inoculum concentration, $2.5 \times 10^{4}$ macroconidia/ml, was used. The design for this experiment was a completely randomized design in which the inoculated and noninoculated controls were separated by a tray within the bucket to avoid cross contamination. There were three towels per treatment per experiment. The experiment was repeated.

Table 1. Analysis of variance for the effects of inoculum concentration and temperature on disease severity index following inoculation of soybean seed with Fusarium graminearum in a rolled-towel assay

\begin{tabular}{lcccc}
\hline Source $^{\mathbf{z}}$ & df & MS & $\boldsymbol{F}$ value & $\boldsymbol{P \text { value }}$ \\
\hline Block (B) & 1 & 0.17 & $\ldots$ & $\ldots$ \\
Temperature (T) & 2 & $<0.001$ & 0.01 & 0.991 \\
B $\times$ T (error 1) & 2 & 0.003 & $\ldots$ & $\ldots$ \\
Concentration (C) & 4 & 1.262 & 159.55 & $<0.001$ \\
T $\times$ C & 8 & 0.006 & 0.83 & 0.597 \\
Error 2 & 12 & 0.09 & $\ldots$ & $\ldots$ \\
\hline
\end{tabular}

${ }^{\mathrm{z}}$ The experimental design was a randomized complete block, with temperature and inoculum concentration in a split-plot arrangement and time as the blocking factor. Disease severity data were arcsine transformed. Inoculum concentrations were evaluated at $0,2.5 \times 10^{2}, 2.5$ $\times 10^{3}, 2.5 \times 10^{4}$, and $2.5 \times 10^{5}$ macroconidia/ml. Temperatures were evaluated at 18,22 , and $25^{\circ} \mathrm{C}$.
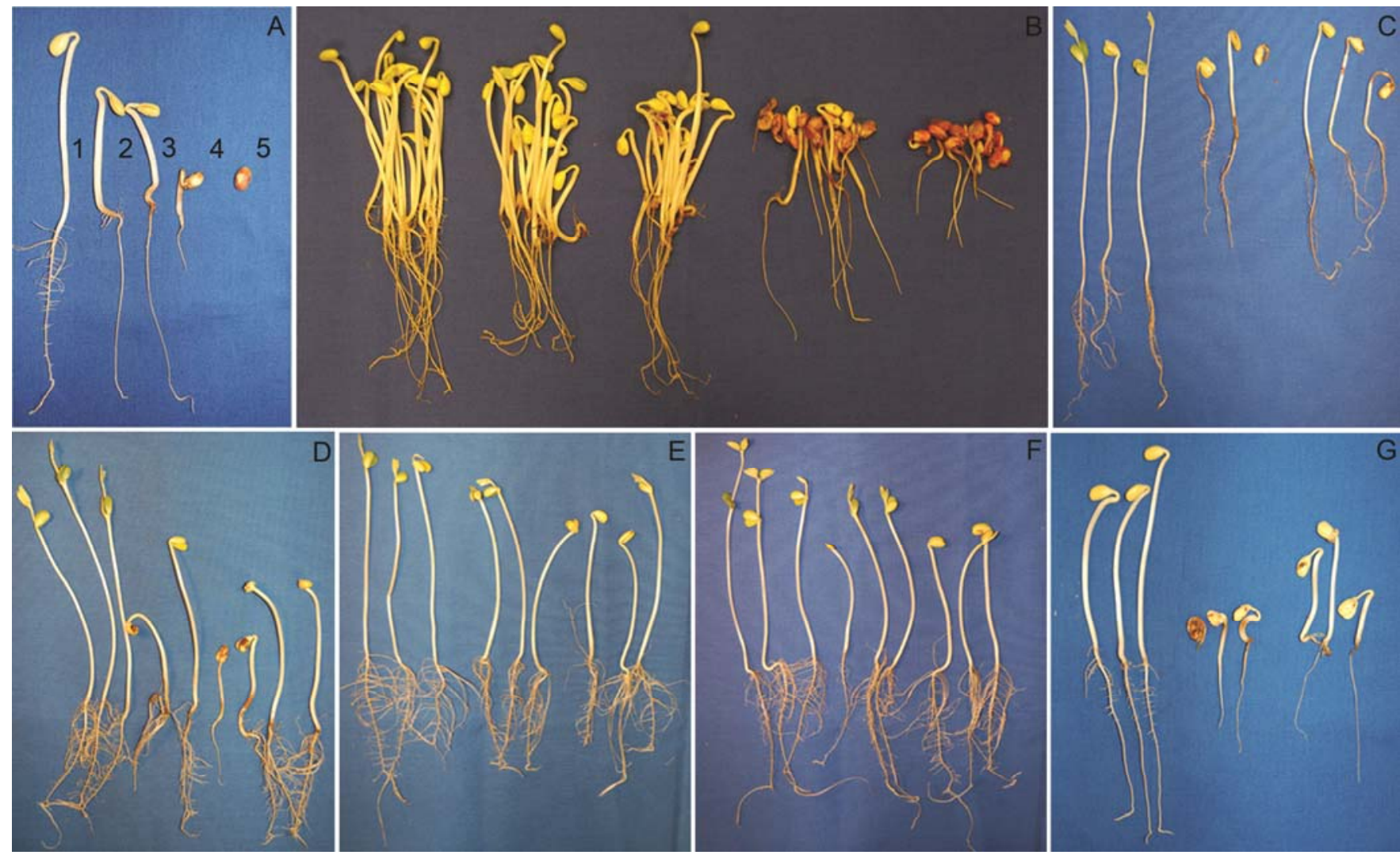

Fig. 2. Diseased seedlings infected by Fusarium graminearum. A, Ordinal scale used to rate seed and seedling infection caused by $F$. graminearum with $1=$ healthy plant, no visible signs of colonization or decreased germination and $5=$ no germination, complete colonization of the seed. B, Soybean seedlings inoculated at different levels starting from the left with $0,2.5 \times 10^{2}, 2.5 \times 10^{3}, 2.5 \times 10^{4}$, and $2.5 \times 10^{5}$ macroconidia/ml that were grown at $22^{\circ} \mathrm{C}$. C-G, Soybean seed treatments from left to right in each picture show the noninoculated control, inoculated with $2.5 \times 10^{4}$ macroconidia/ml with the isolate K95R, and inoculated with $2.5 \times 10^{4}$ macroconidia/ml with the isolate Fay11: C, noninoculated; D, metalaxyl plus fludioxonil; E, captan; F, fludioxonil (high rate); and G, azoxystrobin (high rate). 
The disease severity index data was arcsine-transformed and analyzed using PROC GLM of SAS (SAS Institute Inc.). Levene's test of homogeneity of variance was used to compare experiments. Because there was no significant difference $(P=0.70)$ between experiments, they were analyzed together. The transformed means were compared using Fisher's protected LSD at $P=0.05$.

\section{Results}

Inoculum concentration and temperature. Based on the arcsine-transformed data for disease severity index, the main effect of temperature and the interaction between inoculum concentration and temperature were not statistically significant $(P<0.05)$. However, the main effect of inoculum concentration on disease development was highly significant $(P<0.001)$ (Table 1$)$. As expected, higher disease severity developed at the highest inoculum concentrations (Fig. 3). At the lowest concentration of $2.5 \times 10^{2}$ macroconidia/ml, the mean disease severity was $13.8 \%$ across all temperatures and lesions were small, averaging between 5 and $10 \mathrm{~mm}$ in length or absent (Fig. 2B). At higher inoculum concentrations of $2.5 \times 10^{4}$ and $2.5 \times 10^{5}$ macroconidia/ml, disease severity was

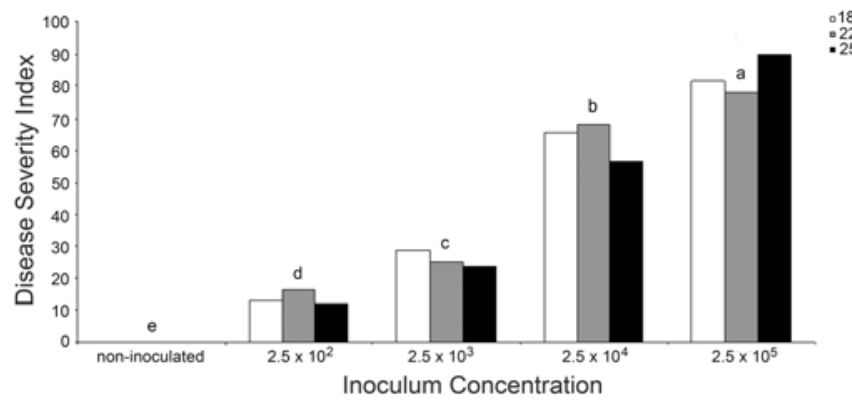

Fig. 3. Bar graph of the disease severity of soybean seedlings with respect to inoculum concentration and temperature following inoculation of soybean seed with Fusarium graminearum. Disease severity values are the mean area of disease divided by the total area $\times 100$. Groups of bars followed by the same letter are not significantly different according to Fisher's protected least significant difference $(P<$ 0.05 ), based on the arcsine-transformed data. The experimental design was a randomized complete block design with two factors, including concentration and temperature. The experiment was repeated over time. greater than $50 \%$ (Fig. 3). Symptoms at these higher inoculum concentrations included water-soaked lesions that were dark-brown to pinkish-brown in color and covered a majority or the entire soybean seedling. Seed were often completely colonized by the fungus and were discolored red to pink, with the mycelium often present on the seed (Fig. 2B).

Isolate pathogenicity. All of the isolates were able to infect and colonize soybean seedlings to different degrees. Based on the arcsine-transformed data for the disease severity index, the isolates were significantly different $(P=0.016)$, with the highest mean, $75.1 \%$ seedling affected by K85R, from corn and the lowest by the isolate Woo from wheat, at $44.8 \%$ for disease severity (Fig. 4). There was a significant difference $(P<0.05)$ between the isolate Woo and three of the six isolates (Fig. 4). This isolate produced fewer macroconidia than the other isolates, which may have contributed to the relatively lower level of disease compared with the other isolates.

Fungicide efficacy. For the fungicide efficacy assay, there were significant interactions for isolate-fungicide $(P=0.042)$ and isolate-concentration-fungicide $(P=0.006)$ for the arcsine-transformed data for the disease severity index (Table 2). The main effects of isolate, inoculum concentration, and fungicide were also significant $(P<0.001)$, with the fungicide having the most significant effect, with a greater than twofold difference in the $F$ value (Table 2). All fungicides were significantly $(P<0.05)$ different from the nontreated controls, indicating that they all provided some level of protection. Seed treated with captan or fludioxonil had significantly lower disease severity across all isolates and concentrations, while seed treated with azoxystrobin had the highest (Table 3; Fig. $2 \mathrm{C}-\mathrm{G})$. There was no significant difference $(P<0.05)$ between the high and low fungicide rates for fludioxonil or captan, based on arcsine-transformed data for disease severity (Table 3). Contrasts were used to evaluate the ordinal rating scale. All seed treatments were significantly different from the nontreated controls $(P<0.0001)$, similar to the data for disease severity. The only difference was that the low and high fludioxonil rates were significantly different from each other $(P=0.0085)$ using the ordinal scale to rate disease (Table 4).

For the strobilurin fungicide seed treatment assay, there was a significant effect of treatment on the arcsine-transformed disease severity index $(P=0.046)$. Trifloxystrobin and pyraclostrobin had

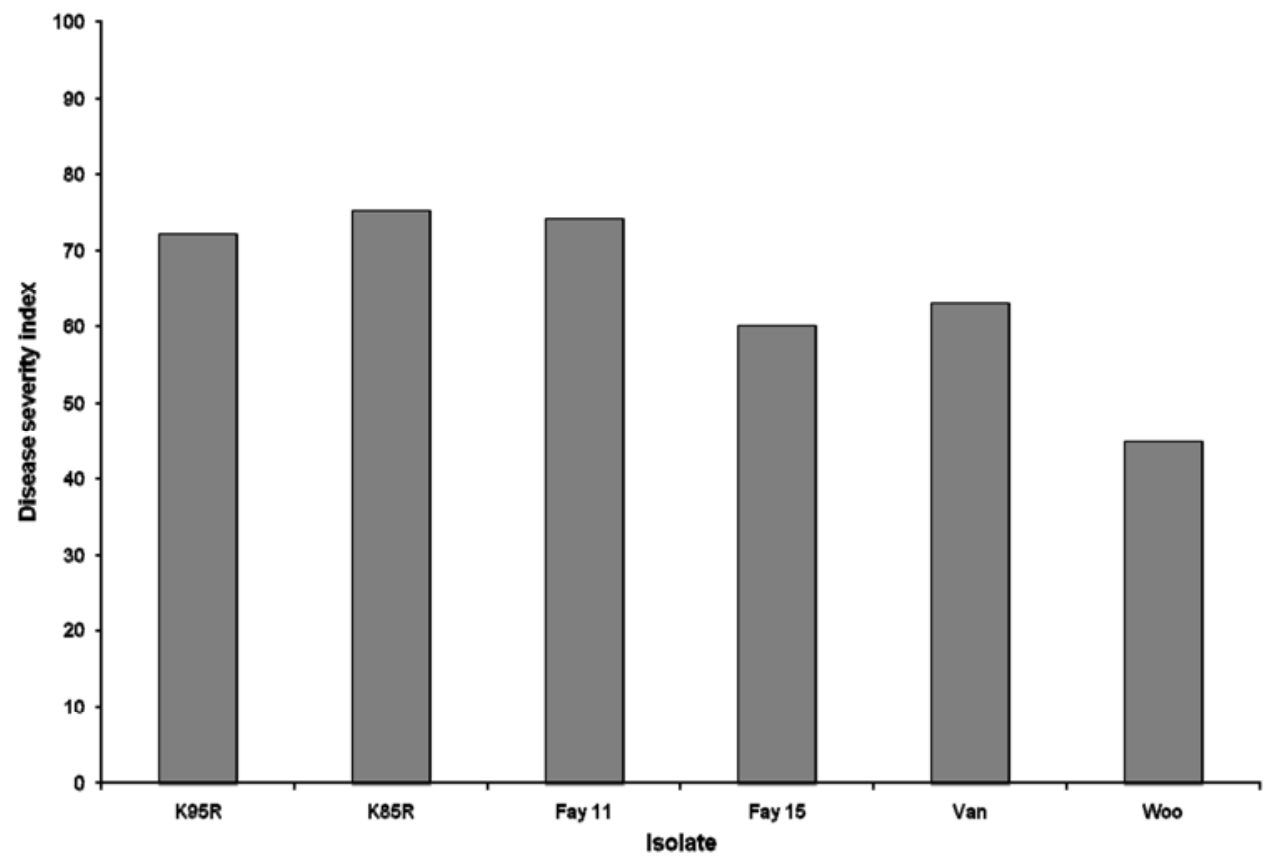

Fig. 4. Bar graph of the disease severity of soybean seedlings with respect to isolate following inoculation of soybean seed with Fusarium graminearum. Disease severity values are the mean area of disease divided by the total area $\times 100$. The experimental design was a complete randomized design with three replications that was repeated. The noninoculated control had no disease. 
significantly lower disease severity than the nontreated seed $(P<$ $0.05)$; however, there was no significant difference $(P<0.05)$ among the strobilurin seed treatments (Table 5), based on contrasts (data not shown).

Table 2. Analysis of variance for effects of fungicide seed treatments, isolate, and inoculum concentration on disease severity index following inoculation of soybean seed with Fusarium graminearum isolates K95R and Fay11 in a rolled-towel assay

\begin{tabular}{lcccc}
\hline Source $^{\mathbf{z}}$ & df & MS & $\boldsymbol{F}$ value & $\boldsymbol{P}$ value \\
\hline Isolate (I) & 1 & 0.19 & 16.80 & $<0.001$ \\
Concentration (C) & 1 & 0.30 & 26.81 & $<0.001$ \\
I $\times$ C & 1 & 0.02 & 1.39 & 0.240 \\
Fungicide (F) & 6 & 2.15 & 189.37 & $<0.001$ \\
I $\times$ F & 6 & 0.03 & 2.22 & 0.042 \\
C $\times$ F & 6 & 0.01 & 1.00 & 0.424 \\
I $\times$ C $\times$ F & 6 & 0.04 & 3.12 & 0.0059 \\
\hline
\end{tabular}

${ }^{\mathrm{z}}$ The experimental design was completely randomized with three factors: isolate, concentration, and fungicide seed treatment. Disease severity data were arcsine transformed. Concentrations were evaluated at $2.5 \times 10^{4}$ and $2.5 \times 10^{5}$. Soybean seed was nontreated or treated with one of the following fungicide seed treatments: captan at $61.9 \mathrm{~g}$ a.i. (Captan 400; Bayer Crop Science), fludioxonil at $2.5 \mathrm{~g}$ a.i. (Maxim 4S; Syngenta Crop Protection Inc.), fludioxonil at $5.0 \mathrm{~g}$ a.i. (Maxim 4S; Syngenta Crop Protection Inc.), azoxystrobin at $1.0 \mathrm{~g}$ a.i (Dynasty; Syngenta Crop Protection Inc.), azoxystrobin at $3.0 \mathrm{~g}$ a.i. (Dynasty; Syngenta Crop Protection Inc.), or mefenoxam + fludioxonil at $3.75 \mathrm{~g}$ a.i. $+2.5 \mathrm{~g}$ a.i. (Apron Maxx RTA; Syngenta Crop Protection Inc.) per $100 \mathrm{~kg}$.

\section{Discussion}

This study addressed two important questions concerning the emergence of $F$. graminearum as a soybean pathogen: optimum inoculum and temperature parameters for disease development and the efficacy of fungicide seed treatments in a seed-based assay. The results indicate that high levels of inoculum are necessary for seed and seedling infections to occur at temperatures conducive for seedling emergence. Severe symptoms on seedlings developed only when inoculum concentrations of $2.5 \times 10^{4}$ macroconidia/ml or higher were used. When the inoculum concentration was below this level, only small, minute lesions developed on a few seedlings. It is unlikely that these small lesions would impede seedling growth. Field inoculum includes ascospores, macroconidia, and hyphal fragments on crop debris (31). When seed are planted into no-till fields, they often come into contact with all of these inoculum units. The rolled-towel assay uses macroconidia, from which mycelium developed within 2 to 3 days after inoculation.

In wheat, the reemergence of Fusarium head blight and, in corn, increased prevalence of ear and stalk rot, all caused by $F$. graminearum, are linked due to widespread adoption of conservation tillage $(14,26)$. This fungus survives in crop residue left on the surface, thus increasing the inoculum density and, consequently, disease intensity, in fields planted into residue from previous host crops (29). Hence, it is highly likely that the emergence of the organism as a pathogen of soybean is also associated with the widespread uses of minimum- and no-till cropping systems and the corresponding increase due to in-field inoculum density.

Table 3. Mean disease severity following inoculation of soybean seed with Fusarium graminearum in a rolled-towel assay

\begin{tabular}{|c|c|c|c|c|c|}
\hline \multirow[b]{3}{*}{ Fungicide treatment ${ }^{\mathrm{z}}$} & \multicolumn{5}{|c|}{ Mean percent seedling affected ${ }^{y}$} \\
\hline & \multicolumn{2}{|c|}{ F. graminearum K95R } & \multicolumn{2}{|c|}{ F. graminearum Fay11 } & \multirow[b]{2}{*}{ Mean } \\
\hline & $2.5 \times 10^{5}$ & $2.5 \times 10^{4}$ & $2.5 \times 10^{5}$ & $2.5 \times 10^{4}$ & \\
\hline Nontreated & $65.5 \mathrm{aA}$ & $55.0 \mathrm{aB}$ & $52.7 \mathrm{aBC}$ & $43.9 \mathrm{aC}$ & 54.3 \\
\hline Metalaxyl plus fludioxonil & $17.3 \mathrm{dAB}$ & $19.3 \mathrm{cA}$ & $22.9 \mathrm{cA}$ & $11.1 \mathrm{~dB}$ & 17.7 \\
\hline Captan & $10.0 \mathrm{de} A$ & $5.8 \mathrm{dA}$ & $8.0 \mathrm{dA}$ & $9.3 \mathrm{dA}$ & 8.3 \\
\hline Fludioxonil (high rate) & $6.8 \mathrm{eA}$ & $6.1 \mathrm{dA}$ & $6.9 \mathrm{dA}$ & $3.9 \mathrm{dA}$ & 5.9 \\
\hline Fludioxonil (low rate) & $9.1 \mathrm{eA}$ & $4.3 \mathrm{~dB}$ & $3.7 \mathrm{~dB}$ & $6.4 \mathrm{dAB}$ & 5.9 \\
\hline Azoxystrobin (low rate) & $55.1 \mathrm{bA}$ & $37.7 \mathrm{bB}$ & $37.2 \mathrm{bB}$ & $35.5 \mathrm{bB}$ & 41.3 \\
\hline Azoxystrobin (high rate) & $42.2 \mathrm{cA}$ & $31.8 \mathrm{bBC}$ & $32.8 \mathrm{bAB}$ & $22.9 \mathrm{cC}$ & 32.4 \\
\hline Mean & 29.4 & 22.8 & 23.5 & 19.0 & $\ldots$ \\
\hline
\end{tabular}

y Mean disease severity represents the lesion length divided by the total length of the seedling multiplied by 100 . Disease severity data were arcsine transformed; the actual means are reported in the table. The experimental design was completely randomized with three factors: isolate, concentration, and fungicide seed treatment. Values followed by the same lowercase letter for treatment and uppercase letter for isolate and concentration are not significantly different according to Fisher's protected least significant difference $(P<0.05)$ based on the arcsine-transformed data.

${ }^{z}$ Soybean seed was nontreated or treated with one of the following fungicide seed treatments: captan at $61.9 \mathrm{~g}$ a.i. (Captan 400; Bayer Crop Science), fludioxonil at 2.5 g a.i. (Maxim 4S; Syngenta Crop Protection Inc.), fludioxonil at 5.0 g a.i. (Maxim 4S; Syngenta Crop Protection Inc.), azoxystrobin at $1.0 \mathrm{~g}$ a.i (Dynasty; Syngenta Crop Protection Inc.), azoxystrobin at $3.0 \mathrm{~g}$ a.i. (Dynasty; Syngenta Crop Protection Inc.), or mefenoxam + fludioxonil at 3.75 g a.i. + 2.5 g a.i. (Apron Maxx RTA; Syngenta Crop Protection Inc.) per $100 \mathrm{~kg}$.

Table 4. Seed treatment comparisons using an ordinal rating scale for diseased soybean seedlings with respect to fungicide following inoculation of soybean seed with Fusarium graminearum in a rolled-towel assay

\begin{tabular}{lrr}
\hline Contrast $^{\mathbf{y}}$ & ATS $^{\mathbf{z}}$ & $\boldsymbol{P}$ value \\
\hline Control vs. all treatments & $2,704.34$ & $<0.0001$ \\
Control vs. fludioxonil (avg) & $4,528.57$ & $<0.0001$ \\
Control vs. azoxystrobin (avg) & 180.63 & $<0.0001$ \\
Metalaxyl plus fludioxonil vs. fludioxonil (low) & 385.45 & $<0.0001$ \\
Metalaxyl plus fludioxonil vs. captan & 356.38 & $<0.0001$ \\
Captan vs. fludioxonil (low) & 0.09 & 0.7590 \\
Captan vs. azoxystrobin (low) & $1,538.08$ & $<0.0001$ \\
Fludioxonil (low) vs. azoxystrobin (low) & $1,725.65$ & $<0.0001$ \\
Fludioxonil (low) vs. fludioxonil (high) & 6.94 & 0.0085 \\
Azoxystrobin (low) vs. azoxystrobin (high) & 23.77 & $<0.0001$ \\
\hline
\end{tabular}

${ }^{\mathrm{y}}$ Low $=$ the low recommended and High $=$ the high recommended fungicide seed treatment rate for fludioxonil and azoxystrobin; Avg $=$ the combined average of the low and high recommended fungicide seed treatment rates for fludioxonil and azoxystrobin. Soybean seed was nontreated or treated with one of the following fungicide seed treatments: captan at $61.9 \mathrm{~g}$ a.i. (Captan 400; Bayer Crop Science), fludioxonil at $2.5 \mathrm{~g}$ a.i. (Maxim 4S; Syngenta Crop Protection Inc.), fludioxonil at $5.0 \mathrm{~g}$ a.i. (Maxim 4S; Syngenta Crop Protection Inc.), azoxystrobin at $1.0 \mathrm{~g}$ a.i (Dynasty; Syngenta Crop Protection Inc.), azoxystrobin at $3.0 \mathrm{~g}$ a.i. (Dynasty; Syngenta Crop Protection Inc.), or mefenoxam + fludioxonil at $3.75 \mathrm{~g}$ a.i. $+2.5 \mathrm{~g}$ a.i. (Apron Maxx RTA; Syngenta Crop Protection Inc.) per $100 \mathrm{~kg}$.

${ }^{\mathrm{z}}$ Analysis of variance-type statistic (30). 
The range of temperatures evaluated in this study was representative of conditions that occur at the time of planting in Ohio. Infections of soybean from $F$. graminearum were similar across all temperatures evaluated in this study. Because seedling growth is reduced at lower temperatures, more time is available for the fungus to infect them. However, fungal growth of $F$. graminearum was also reduced at lower temperatures in these studies. The optimum temperature range for growth of $F$. graminearum is reported to be 20 to $25^{\circ} \mathrm{C}(6,22)$. Thus, the seedlings and fungus would be expected to grow proportionally to one another at the different temperatures and low temperatures would not favor infections.

The rolled-towel inoculation method developed in this study provides a timely and effective method that can be used by researchers and industry to develop and test new fungicide chemistries, as well as other parameters that may provide a better understanding of $F$. graminearum and its role as a seed and seedling pathogen to soybean. Fungicide seed treatments labeled for soybean are changing as older chemistries are replaced with new active ingredients. Seed treated with captan and fludioxonil had the lowest disease severity compared with azoxystrobin. The newer class of fungicides, known as strobilurins, did not effectively protect the seed from infection caused by $F$. graminearum. It is important to note that some of the results from the rolled-towel assays were different from the previously reported amended agar assays using some of the same isolates (8). In this study, captan performed equally as well as fludioxonil as a seed treatment whereas, in the amended agar assays, fludioxonil was the only fungicide that sufficiently inhibited mycelial growth (8). This study found results similar to those of the amended agar assays for azoxystrobin, trifloxystrobin (8), and pyraclostrobin (M. L. Ellis and A. E. Dorrance, unpublished), in which there was not a significant reduction in mycelial growth compared with the nonamended controls. The mode of action of strobilurin is targeted toward spore germination by inhibiting mitochondrial respiration, which occurs by blocking electron transfer in cytochromes b and c1 (40). Unlike the plate assays which measure mycelial growth, the rolled-towel method in this study evaluated the fungicides' effect directly on macroconidia.

The strobilurin fungicides did not provide complete control, although disease severity was significantly reduced relative to the untreated check for two of the three fungicides. In addition, the seed-treatment fungicides Rival and Captan are no longer commonly used or available for soybean. Crop production is still predominately no-till or reduced tillage; therefore, a continued increase in severity of seed and seedling disease caused by $F$. graminearum is expected. This will provide both a need and a challenge for industry to develop new chemistries for seed treatments that are broad spectrum for protection against the wide array of seedling pathogens. Another challenge industry will face when designing new products is the pathogen's ability to mutate and

Table 5. Mean disease severity following inoculation of soybean seed with Fusarium graminearum for soybean seed treated with strobilurin fungicides in a rolled-towel assay ${ }^{y}$

\begin{tabular}{lc}
\hline Treatment $^{\mathbf{z}}$ & Percent seedling affected \\
\hline Nontreated & $25.3 \mathrm{~A}$ \\
Azoxystrobin & $13.7 \mathrm{AB}$ \\
Pyraclostrobin & $7.6 \mathrm{~B}$ \\
Trifloxystrobin & $7.3 \mathrm{~B}$ \\
Mean & 13.5 \\
\hline
\end{tabular}

${ }^{y}$ Mean disease severity represents the lesion length divided by the total length of the seedling. Disease severity data were arcsine transformed; the actual means are reported in the table. The experimental design was completely randomized with three replications. Values followed by the same letter are not significantly different according to Fisher's protected least significant difference $(P<0.05)$, based on the arcsine-transformed data.

${ }^{\mathrm{z}}$ Soybean seed was nontreated or treated with one of the following strobilurin fungicides: azoxystrobin at $3.0 \mathrm{~g}$ a.i. (Dynasty; Syngenta Crop Protection Inc.), trifloxystrobin at $10.0 \mathrm{~g}$ a.i. (Trilex; Bayer Crop Science), or pyraclostrobin at $9.9 \mathrm{~g}$ a.i. (Stamina; BASF Corp.) per $100 \mathrm{~kg}$. overcome the fungicides' ability to protect the seed from infection. Previous work by Broders et al. (8) demonstrated that this is possible via the generation of fludioxonil mutants under laboratory conditions and, in this study, the low rate of fludioxonil was significantly different from the high rate using orthogonal contrasts. Although no fludioxonil mutants were recovered from the field to date, this could be a challenge in managing soybean seed and seedling diseases. Alternative strategies may be needed because Zhang et al. (41) have reported that novel strains of Bacillus subtilis inhibited mycelial growth and macroconidial germination of $F$. graminearum and $F$. oxysporum in both in vitro and greenhouse assays.

Various factors may have prevented $F$. graminearum from emerging as a soybean pathogen prior to 2007: high inoculum levels required for disease to develop, seed infected by $F$. graminearum may not have emerged from the soil, oomycete-selective media may have prevented the isolation of this pathogen, symptoms caused by $F$. graminearum are common to several other soybean pathogens, and fungicides previously used in soybean were highly effective. No-till and reduced-tillage practices currently used in Ohio optimize favorable soil conditions for pathogen growth and survival $(15,36)$, likely increasing the amount of inoculum in the field. With increased inoculum levels and the previously effective fungicides Rival and Captan no longer commonly used, it is possible that $F$. graminearum was able to emerge as a pathogen to soybean. Due to the limited choice of seed-treatment fungicides, identifying integrated management strategies for this newly emerged pathogen of soybean should be a priority.

\section{Acknowledgments}

We thank F. Cruz, C. Cruz, W. Pipatpongpinyo, M. Benítez, M. Ortega, G. Austin, and S. Dawes for technical assistance. This project was funded by State and Federal Funds appropriated to the Ohio Agricultural Research and Development Center, The Ohio State University. Funding was also provided, in part, through soybean check-off dollars from Ohio Soybean Council.

\section{Literature Cited}

1. Agarwal, D. K. 1976. Fusarium root rot of soybean-a new record from India. Indian Phytopathol. 29:471.

2. Ali, S., Rivera, V. V., and Secor, G. A. 2005. First report of Fusarium graminearum causing dry rot of potato in North Dakota. Plant Dis. 89:105.

3. Anderson, T. R., Olechowski, H., and Welacky, T. 1988. Incidence of Rhizoctonia and Fusarium root rot of soybean in southwestern Ontario, 1986. Can. Plant Dis. Surv. 68:143-145.

4. Bai, G. H., and Shaner, G. 1994. Scab of wheat: prospects for control. Plant Dis. 78:760-765.

5. Baird, R. E., Mullinix, B. G., Peery, A. B., and Lang, M. L. 1997. Diversity and longevity of the soybean debris mycobiota in a no-tillage system. Plant Dis. 81:530-534.

6. Beyer, M., Röding, S., Ludewig, A., and Verreet, J.-A., 2004. Germination and survival of Fusarium graminearum macroconidia as affected by environmental factors. Phytopathology 152:92-97.

7. Broders, K. D., Lipps, P. E., Paul, P. A., and Dorrance, A. E. 2007. Characterization of Pythium spp. associated with corn and soybean seed and seedling disease in Ohio. Plant Dis. 91:727-735.

8. Broders, K. D., Lipps, P. E., Paul, P. A., and Dorrance, A. E. 2007. Evaluation of Fusarium graminearum associated with corn and soybean seed and seedling disease in Ohio. Plant Dis. 91:1155-1160.

9. Carter, J. P., Rezanoor, H. N., Holden, D., Desjardins, A. E., Plattner, R. D. and Nicholson, P. 2002. Variation in pathogenicity associated with the genetic diversity of Fusarium graminearum. Eur. J. Plant Pathol. 108:573583.

10. Chamberlain, D. W. 1972. Heat-induced susceptibility to non-pathogens and cross-protection against Phytophthora megasperma var. sojae in soybean. Phytopathology 62:645-646.

11. Chongo, G., Gossen, B. D., Kutcher, H. R., Gilbert, J., Turkington, T. K., Fernandez, M. R., and McLaren, D. 2001. Reaction of seedling roots of 14 crop species to Fusarium graminearum from wheat heads. Can. J. Plant Pathol. 23:132-137.

12. Clear, R. M., Nowicki, T. W., and Daun, J. K. 1989. Soybean discoloration by Alternaria spp., and Fusarium spp., effects on quality and production of fusariotoxins. Can. J. Plant Pathol. 11:308-312.

13. Cotten, T. K., and Munkvold, G. P. 1998. Survival of Fusarium moniliforme, F. proliferatum, and $F$. subglutinans in maize stalk residue. Phytopathology 88:550-555.

14. Dill-Macky R., and Jones R. K. 2000. The effect of previous crop residues and tillage on Fusarium head blight of wheat. Plant Dis. 84:71-76.

15. Fernandez, M. R., and Fernandes, J. M. C. 1990. Survival of wheat patho- 
gens in wheat and soybean residues under conservation tillage systems in southern and central Brazil. Can. J. Plant Pathol. 12:289-294.

16. Garcia-Romera, I., Garcia-Garrido, J. M., Martin, J., Fracchia, S., Mujica, M. T., Godeas, A., and Ocampo, J. A. 1998. Interactions between saprotrophic Fusarium strains and arbuscular mycorrhizas of soybean plants. Symbiosis 24:235-245.

17. Hanson, L. E. 2006. Fusarium yellowing of sugar beet caused by Fusarium graminearum from Minnesota and Wyoming. Plant Dis. 90:686.

18. Harrington, T. C., Steimel, J., Workneh, F., and Yang, X. B. 2000. Molecular identification of fungi associated with vascular discoloration of soybean in the north central United States. Plant Dis. 84:83-89.

19. Jacobsen, B. J., Harlin, K. S., Swanson, S. P., Lambert, R. J., Beasley, V. R., Sinclair, J. B., and Wei, L. S. 1995. Occurrence of fungi and mycotoxins associated with field mold damaged soybeans in the Midwest. Plant Dis. 79:86-88.

20. Jones, R. K. 1999. Seedling blight development and control in spring wheat damaged by Fusarium graminearum group 2. Plant Dis. 83:1013-1018.

21. Leslie, J. F., Pearson, C. A. S., Nelson, P. E., and Toussoun, T. A. 1990 Fusarium spp. from corn, sorghum, and soybean fields in the central and eastern United States. Phytopathology 80:343-350.

22. Leslie, J. F., and Summerell, B. A. 2006. The Fusarium Laboratory Manual. Blackwell Publishing, Ames, IA.

23. Martinelli, J. A., Bocchese, C. A.C., Xie, W., O'Donnell, K., and Kistler, H. C. 2004. Soybean pod blight and root rot caused by lineages of Fusarium graminearum and the production of mycotoxins. Fitopatol. Bras. 29:492498

24. McMullen, M. P., Jones, R., and Gallenberg, D. 1997. Scab of wheat and barley: a re-emerging disease of devastating impact. Plant Dis. 81:13401348.

25. Miller, J. D., Culley, J., Fraser, K., Hubbard, S., Meloche, F., Ouellet, T., Seaman, W. L., Seifert, K. A., Turkington, K., and Voldeng, H. 1998. Effect of tillage practice on Fusarium head blight of wheat. Can. J. Plant Pathol. 20:95-103.

26. Munkvold, G. P. 2003. Cultural and genetic approaches to managing mycotoxins in maize Annu. Rev. Phytopathol. 41:99-116.

27. Osorio, J. A., and McGee, D. C. 1992. Effects of freeze damage on soybean seed mycoflora and germination. Plant Dis. 76:879-882

28. Pioli, R. N., Mozzoni, L., and Morandi, E. N. 2004. First report of pathogenic association between Fusarium graminearum and soybean. Plant Dis. $88: 220$.

29. Schaafsma A. W., Tamburic-Ilincic L., and Hooker D. C. 2005. Effect of previous crop, tillage, field size, adjacent crop, and sampling direction on airborne propagules of Gibberella zeae/Fusarium graminearum, Fusarium head blight severity, and deoxynivalenol accumulation in winter wheat. Can. J. Plant Pathol. 27:217-224.

30. Shah, D. A., and Madden, L. V. 2004. Nonparametric analysis of ordinal data in designed factorial experiments. Phytopathology 94:33-43.

31. Sutton, J. C. 1982. Epidemiology of wheat head blight and maize ear rot caused by Fusarium graminearum. Can. J. Plant Pathol. 4:195-209.

32. Tuite, J. 1969. Plant Pathological Methods-Fungi and Bacteria. Burgess Publ. Co., Minneapolis, MN.

33. Wicklow, D. T., Bennett, G. A., and Shotwell, O. L. 1987. Secondary invasion of soybean by Fusarium graminearum and resulting mycotoxin contamination. Plant Dis. 71:1146.

34. Wildermuth, G. B., and McNamara, R. B. 1987. Susceptibility of winter and summer crops to root and crown infection by Bipolaris sorokiniana. Plant Pathol. 36:481-491.

35. Windels, C. E., Kommedahl, T., Stienstra, W. C., and Burnes, P. M. 1988 Occurrence of Fusarium species in symptom-free and overwintered cornstalks in northwestern Minnesota. Plant Dis. 72:990-993.

36. Workneh, F., Tylka, G. L., Yang, X. B., Faghihi J., and Ferris J. M. 1999. Regional assessment of soybean brown stem rot, Phytophthora sojae, and Heterodera glycines using area-frame sampling: prevalence and effects of tillage. Phytopathology 89:204-211.

37. Xue, A. G., Armstrong, K. C., Voldeng, H. D., Fedak, G., and Babcock, C. 2004. Comparative aggressiveness of isolates of Fusarium species causing head blight on wheat in Canada. Can. J. Plant Pathol. 26:81-88.

38. Xue, A. G., Cober, E., Voldeng, H. D., Babcock, C., and Clear, R. M. 2006 Different aggressiveness in isolates of Fusarium graminearum and Fusarium pseudograminearum causing root rot of soybean. Can. J. Plant Pathol. 28:369-369.

39. Xue, A. G., Cober, E., Voldeng, H. D., Babcock, C., and Clear, R. M. 2007. Evaluation of the pathogenicity of Fusarium graminearum and Fusarium pseudograminearum on soybean seedlings under controlled conditions. Can. J. Plant Pathol. 29:35-40.

40. Ypema, H. L., and Gold, R. E. 1999. Kresoxim-methyl, modification of a naturally occurring compound to produce a new fungicide. Plant Dis. 83:4 19.

41. Zhang, J. X., Xue, A. G., and Tambong, J. T. 2009. Evaluation of seed and soil treatments with novel Bacillus subtilis strains for control of soybean root rot caused by Fusarium oxysporum and F. graminearum. Plant Dis. 93:1317-1323. 